\title{
Impact of the fire ant pesticide AMDRO on loggerhead turtle nest productivity and seafinding orientation
}

\author{
Heather E. Smith ${ }^{1}$, Shelby R. Hoover ${ }^{1}$, Michael Salmon ${ }^{1,}{ }^{*}$, Heather Seaman ${ }^{2}$, \\ Christina M. Coppenrath ${ }^{1,2}$, Sarah E. Hirsch ${ }^{2}$, Justin R. Perrault ${ }^{2}$ \\ ${ }^{1}$ Department of Biological Sciences, Florida Atlantic University, Boca Raton, Florida 33431, USA \\ ${ }^{2}$ Loggerhead Marinelife Center, 14200 U.S. Highway 1, Juno Beach, Florida 33408, USA
}

\begin{abstract}
Invasive fire ants prey on a variety of organisms in the southeastern USA, including the pipped eggs and hatchlings within sea turtle nests. The granular fire ant bait AMDRO ${ }^{\mathbb{B}}$ (active ingredient hydramethylnon) is currently used at some rookeries to protect nests, but no studies have been conducted to determine if the pesticide negatively impacts the eggs or the hatchlings. We examined the pesticide's effect on loggerhead (Caretta caretta) nests at Juno Beach, Florida, USA, specifically targeting how exposure affected hatching success, hatchling emergence success, and the ability of the turtles to orient visually from the nest to the sea. Pesticide granules were placed within a $30 \mathrm{~cm}$ diameter circle on the sand directly above the nest during the final 5-10 days of incubation, representative of its typical application at nesting beaches. Cornmeal granules in soybean oil and untreated natural nests served as controls. AMDRO had no significant effect on hatching success or emergence success, nor did it result in any deficiencies in hatchling orientation accuracy. However, the pesticide and cornmeal control attracted other predators (Atlantic ghost crabs and avian species), in addition to fire ants, to the nest site, thus revealing the nest's location and potentially increasing its vulnerability. Consequently, we suggest that its usage may not be beneficial at sites where predators other than ants are especially abundant.
\end{abstract}

KEY WORDS: Rookery management $\cdot$ AMDRO $\cdot$ Fire ant control $\cdot$ Nest protection $\cdot$ Loggerhead turtle

\section{INTRODUCTION}

Sea turtles face a multitude of anthropogenic threats that have led to dramatic reductions in population sizes from historic levels (Allison et al. 2009). These threats include light pollution (McFarlane 1963), climate change (Laloë et al. 2016), by-catch from the seafood industry, and dredging activity (Robins 1995). In addition to these challenges, sea turtles face predation pressure from invasive species as well as natural predators (Fowler 1979). The impact of predators, both native and introduced, on

${ }^{*}$ Corresponding author: salmon@fau.edu sea turtle nests is a continuing concern for biologists and one that warrants considerable attention, given that some sea turtle populations are continuing to decline (Allison et al. 2009, Mazaris et al. 2017).

The red imported fire ant Solenopsis invicta (hereafter, RIFA) is an invasive predator that has infested the majority of sea turtle nesting beaches in the southeastern United States (Allen et al. 2001). S. invicta is native to South America, where loggerheads routinely nest, but is primarily a grassland species within its native range and less likely to interact with sea turtles on nesting beaches. RIFAs

(C) The authors 2020. Open Access under Creative Commons by Attribution Licence. Use, distribution and reproduction are unrestricted. Authors and original publication must be credited. 
in south Florida are likely facing less pressure from interspecific competition, and can therefore reach higher population densities than ants in their native range (Wilder et al. 2011). RIFAs are known to prey on the eggs, developing embryos, and recently hatched young of a variety of reptilian species, including freshwater turtles (Allen et al. 2001, Buhlmann \& Coffmann et al. 2001), gopher tortoises (Dziadzio et al. 2016), racerunner lizards (Mount et al. 1981), rough green snakes (Conners 1998), and caimans (Marcó et al. 2013). RIFAs are often present between the dune and wrack lines, prime locations for sea turtle nests, and are now considered a significant threat at some sea turtle nesting beaches, especially in low-density nesting areas where nest predators can significantly impact population dynamics (Allen et al. 2001).

RIFAs are likely attracted to the surface disturbance and cloacal mucous content of fresh nests and will excavate tunnels to monitor them for the emergence of hatchlings (Allen et al. 2001, Buhlmann \& Coffmann 2001). Since at least 1979, anecdotal and experimental evidence has shown that fire ants readily prey on sea turtle nests. RIFAs have been observed feeding on recently pipped eggs and newly emerged hatchlings of loggerhead sea turtles Caretta caretta (Parris et al. 2002) and are capable of penetrating intact loggerhead sea turtle eggs (Diffie et al. 2010).

The Florida Fish and Wildlife Conservation Commission (FWC) currently recommends fire ant removal by either pouring $\sim 3001$ of near-boiling water $\left(>82^{\circ} \mathrm{C}\right)$ onto mounds or by physically removing mounds with a shovel and bucket (FWC 2016). These methods are not only impractical at many nesting sites, but also potentially risky to wildlife management personnel and the sea turtle nests they are trying to protect. An alternative to physical removal of fire ant mounds is use of the pesticide hydramethylnon (known commonly by the brand name $\mathrm{AMDRO}^{\circledR}$ ) to eradicate mounds in proximity to sea turtle nests. Due to the difficultly of locating the ant mounds themselves, which are often hidden in dune vegetation, the pesticide is often placed directly on sea turtle nests or ant tracks along the beach when ant activity is observed. This is typically done during the later stages of embryonic development, when it is most effective to prevent predation. Pre-emptively treating nests with AMDRO at earlier stages of incubation is time consuming, costly, and would likely be less effective at preventing predation, as other ants could move in to occupy an open niche.

Data show that a reduction in RIFA populations through the use of hydramethylnon leads to an in- crease in herpetofaunal abundance (Allen et al. 2017). However, hydramethylnon is also known to be mildly to highly toxic to some vertebrate species (Lim 2004). Elevated doses of dermal hydramethylnon resulted in reduced food intake, weight loss, reduced platelet counts, reduced heart weight, and increased liver weight in rabbits (EPA 1998). Hydramethylnon is also known to affect the eyes of rabbits, causing irritation, corneal redness, and discharge (Tomlin 2003). Alterations in visual perception could be detrimental to the survival of hatchling sea turtles exposed to hydramethylnon, since hatchlings primarily use visual cues to orient from the nest to the surf zone in the initial phase of their offshore migration (Lucas et al. 1992). Because hatchling sea turtles remain just below the surface of the sand for extended periods, waiting for sand temperatures to decrease to initiate their emergence (Mrosovsky 1968), they may experience dermal and ocular exposure to ant baits placed on surface sand. Additionally, experimental data have suggested that the parchment-shelled eggs of some turtle species may be relatively permeable to environmental toxicants, including pesticides, and that these toxicants can have an impact on hatching success, body mass, and locomotor performance (Wu et al. 2016, de Solla et al. 2011). However, there are currently no data on the effects of hydramethylnon on the behavior or physiology of any reptile species.

This study investigated the effect of hydramethylnon on the nest survival and hatchling behavior of loggerhead sea turtles to determine if the application of this pesticide on sea turtle nests is a safe alternative to the physical removal of fire ant mounds. The project was undertaken to help wildlife management personnel make informed decisions with regard to the use of this pesticide and ant removal on vulnerable sea turtle nesting beaches. While the incidence of RIFA predation on sea turtle nests on densely populated South Florida beaches is low (Allen et al. 2001), the information gleaned from this study could have a broad impact and potentially inform conservation efforts worldwide, including those in areas where fire ant predation represents a serious threat to local sea turtle populations.

Here, we ask 3 questions: (1) Do sea turtle nests (eggs, hatchlings, or both) exposed to AMDRO experience reduced hatching and emergence success? (2) Does exposure to AMDRO impair visually-based hatchling sea-finding orientation? (3) Does the presence of hydramethylnon at nest sites attract other predators to sea turtle nests? 


\section{MATERIALS AND METHODS}

\subsection{Nest selection and treatment categories}

We conducted this study along a $6.0 \mathrm{~km}$ length of beach adjacent to Loggerhead Marinelife Center (LMC) in Juno Beach, Florida, USA, from JuneAugust of 2018 (Fig. 1). This site has one of the highest nesting densities per $\mathrm{km}$ of loggerhead sea turtles in Florida and worldwide (LMC, unpubl. data).

In June 2018, 125 loggerhead nests were selected for this study. These nests were marked in the early morning the night after they were deposited using standard sea turtle survey practices (FWC 2016). The location of each nest was determined by digging into the sand until the eggs at the top of the egg chamber were located. Wooden stakes served as the clutch markers and were placed $30 \mathrm{~cm}$ due west of the center of the chamber. The study site itself was divided into 6 zones, each $\sim 1.00 \pm 0.36 \mathrm{~km}$ in length, on average. As they were deposited, nests within each zone were randomly assigned to different treatment groups to minimize any effects of differences in local conditions across the entire beach site.

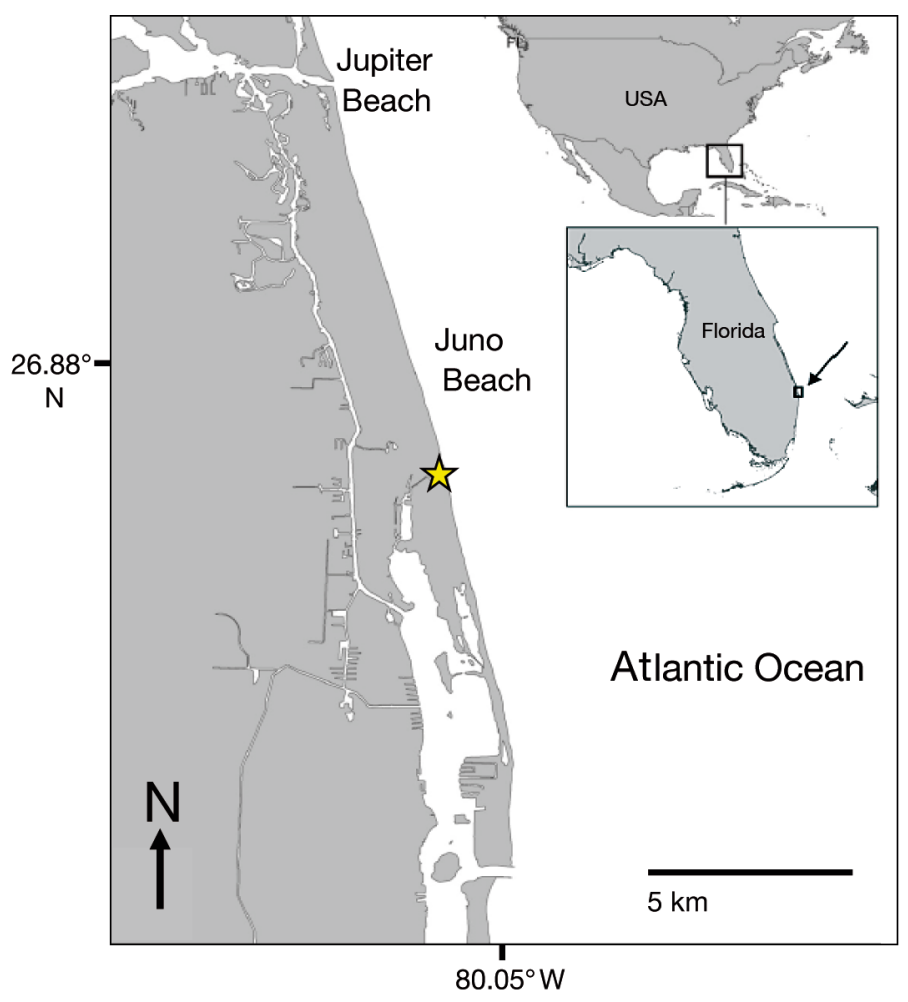

Figure 1. Study site at Juno Beach, Florida, USA, with the star showing the location where the arena assays were performed (modified from Perrault et al. 2011)
Treatments ( $\mathrm{n}=25$ nests per treatment) included a natural control group of nests left to incubate undisturbed, 2 cornmeal control groups, and 2 experimental treatment groups. Cornmeal soaked in soybean oil is the carrier for hydramethylnon in AMDRO (with the soybean oil being the primary fire ant attractant); therefore, these 2 substances were chosen as the vehicle control (i.e. control without the chemical compound of interest). Cornmeal control 1 and AMDRO treatment 1 were treated 3 times, on Days 45, 47, and 49 of incubation. Cornmeal control 2 and AMDRO treatment 2 were treated 6 times, on Days 39, 41, 43, 45, 47, and 49 of incubation. The vehicle control and AMDRO treated nests were spaced well apart at the beach to prevent contamination.

To treat each cornmeal control nest, $25 \mathrm{~g}$ of cornmeal was combined with $5 \mathrm{ml}$ of soybean oil. Between 18:00 and 22:00 $\mathrm{h}$, this mixture was spread within a $\sim 30 \mathrm{~cm}$ diameter circle directly above the nest egg chamber. AMDRO nests were treated likewise with $25 \mathrm{~g}$ of AMDRO. The AMDRO or cornmeal granules were then covered with a very thin layer of sand collected from an adjacent area to prevent wind from carrying the substance away.

This study design was intended to replicate standard practices for the application of AMDRO to sea turtle nests. This pesticide is typically placed on the nest in the later stages of development when it provides more effective protection against ant predation. Based on data collected by LMC surveys, loggerhead turtles on Juno Beach typically incubate for approximately $51 \mathrm{~d}$. During the course of the treatment regimen, however, nests began to emerge unexpectedly early (some after only $44 \mathrm{~d}$ incubation). To ensure that nests were not missing treatments entirely, the treatment schedule was amended on August 5, 2018 by advancing the treatment schedule by $2 \mathrm{~d}$ for the remainder of nests.

Nests were monitored nightly for possible emergences, beginning at Day 45 of incubation. Wooden restraining cages $(53 \mathrm{~cm}$ long $\times 53 \mathrm{~cm}$ wide $\times 8.5 \mathrm{~cm}$ high) covered with black plastic mesh were placed over the egg chambers of pre-emergent nests to capture the hatchlings used for later behavioral tests (see below). The beach was also patrolled using allterrain vehicles (ATVs) from 23:00 until 06:00 h to monitor for hatchling emergences. All nests, regardless of the day of incubation, were also monitored by the LMC morning survey team between 06:00 and 11:00 $\mathrm{h}$ for evidence of a missed emergence so that the exact date of emergence for each nest could be determined. 


\subsection{Quantifying hatching and emergence success}

Any events that may have affected nest production (e.g. depredations or sand accruement) were noted. Nests were excavated and inventoried $3 \mathrm{~d}$ after a mass emergence event. Hatched eggs were counted as the number of $>50 \%$ eggshell fragments remaining in the nest. Unhatched eggs less shelled albumen globs (without yolks) were also counted, as well as the number of live and dead pipped eggs (eggshell torn with hatchling inside) and live and dead hatchlings. Hatching success was evaluated by dividing the number of hatched eggs by the total clutch size; emergence success was evaluated by dividing the number of emerged hatchlings by the total clutch size (Miller 1999). Data were analyzed using a 1-way ANOVA to check for differences in means between treatments (Zar 1999).

\subsection{Testing hatchling orientation capabilities}

Up to 20 hatchlings from each nest were transported in small coolers to a remote area of beach, selected because it was shielded by tall trees from artificial lighting. The procedures used for performing arena assays to test hatchling orientation are described in Reintsma et al. (2014). Briefly, a circle $4 \mathrm{~m}$ in diameter (the 'arena') was drawn in the sand between the surf zone and dune. The sand within was leveled with a broom and any debris was removed. Hatchlings were placed in groups of 6 or fewer turtles in a shallow (1$3 \mathrm{~cm}$ ) pit centered in the arena. Only hatchings that were actively crawling inside their cooler were used in the arena assays in order to specifically test the effects of vision. It is possible that hatchlings were affected by AMDRO in such a way as to prohibit crawling, but these effects are accounted for in measurements of hatching and emergence success.

Once placed in the arena, the turtles almost immediately crawled out of the pit and moved toward the arena boundary, leaving flipper tracks in the sand. These were used to reproduce the turtles' crawl path and to determine an orientation angle, based upon where they exited the arena. The orientation angle was measured using an electronic compass that recorded the vector between the center of the arena and the location where the turtle crossed the arena boundary. Each turtle was tested once and then released at an adjacent dark beach site.

Rayleigh tests were used to determine if the hatchlings from a single nest, tested in 1 arena, were significantly oriented. Watson-Williams tests were used to determine if there were significant differences in orientation between nests from different treatment groups (Zar 1999).

\subsection{Predators at the nest}

Nests were also monitored for signs of predators (tracks, burrows, or the predators themselves) from Day 45 to emergence. The number of observations was generally small, favoring the use of non-parametric tests (chi-square; Fisher's exact tests) to determine if differences between nest treatment and control groups achieved significance (Zar 1999).

\section{RESULTS}

\subsection{Hatching and emergence success}

Some emergences occurred earlier than expected (mean incubation of study nests $=48 \mathrm{~d}, \mathrm{n}=111$ ), leading to some nests receiving more treatments than others (range: 1 to 6 treatments). Nests were defined as AMDRO/cornmeal treatment 1 nests if they received $\leq 3$ treatments or as AMDRO/cornmeal treatment 2 nests if they received $\geq 4$ treatments. Of the 125 nests that were originally marked, 14 were removed from the study as the clutches could not be located after the initial verification. This was primarily due to sand accruement after the remnants of tropical storm Beryl passed over Juno Beach. After these nests were removed from the study, there remained a total of 20 AMDRO treatment 1 nests, 20 AMDRO treatment 2 nests, 24 cornmeal treatment 1 nests, 22 cornmeal treatment 2 nests, and 25 natural control nests.

Overall mean hatching success across all nests ( $\mathrm{n}=$ 111) was $65.2 \pm 2.4 \%$, and overall mean emergence success across all nests was $61.9 \pm 2.4 \%$ (mean $\pm \mathrm{SE}$ ). Mean hatching success shown by all treatment and control groups ranged between 62 and $70 \%$, whereas emergence success ranged between 59 and $67 \%$ (Table 1). There were no significant differences among the AMDRO treatment and control groups in either hatching success (ANOVA $F=0.319, \mathrm{p}=0.87$ ) or emergence success (ANOVA $F=0.336, p=0.85$ ).

\subsection{Sea-finding behavior}

Orientation data were collected from 500 hatchlings from 28 nests, taken from a minimum of 5 nests in each control and each experimental group. Hatch- 
Table 1. Mean hatching and emergence success from nests in the treatment groups. $\mathrm{n}=$ number of nests. All values are mean $\pm \mathrm{SE}$.

\begin{tabular}{|lccc|}
\hline Treatment & $\mathrm{n}$ & $\begin{array}{c}\text { Hatching } \\
\text { success (\%) }\end{array}$ & $\begin{array}{c}\text { Emergence } \\
\text { success (\%) }\end{array}$ \\
\hline AMDRO 1 & 20 & $63.1 \pm 7.3$ & $59.1 \pm 7.0$ \\
AMDRO 2 & 20 & $70.0 \pm 4.3$ & $66.9 \pm 4.4$ \\
Cornmeal 1 & 24 & $64.3 \pm 4.8$ & $60.0 \pm 4.7$ \\
Cornmeal 2 & 22 & $62.0 \pm 5.7$ & $59.9 \pm 5.8$ \\
Natural control & 25 & $66.9 \pm 5.1$ & $63.7 \pm 5.4$ \\
All nests & 111 & $65.2 \pm 2.4$ & $61.9 \pm 2.4$ \\
\hline
\end{tabular}

lings from all of the nests were significantly oriented in a generally eastward direction (Fig. 2; Rayleigh test, $\mathrm{p}<0.01$ ). There was considerable overlap between the $95 \%$ confidence limits among the treatments (Table 2), and nest treatment groups showed no significant difference in the mean angle of orientation (Watson-Williams test, $\mathrm{p}=0.41$ ). A secondorder mean orientation angle was determined for all the nests used in each treatment. Those orientation angles ranged between $86^{\circ}$ and $94^{\circ}$ (Table 2). The second-order r-vector (a measure of variation ranging between 0.01 [random vectors] and 0.99 [highly clustered vectors]; Zar 1999) resulted in values between 0.92 and 0.99 , reflecting that all hatchling groups were well oriented.

\subsection{Predators at the nest site}

Nest predators were observed more often during the dosing period at both AMDRO-treated and cornmeal treated nests than at natural control nests (Table 3; Fisher's exact test, $\mathrm{p}=0.03$ ). The most frequently observed predator was the Atlantic ghost crab Ocypode quadrata. Ghost crabs, their tracks, burrows, or a combination of all 3 were observed at $27.9 \%$ of the AMDRO and cornmeal treatment nests ( $\mathrm{n}=24$ of 86 ) compared to $8.0 \%$ of the natural control nests $(\mathrm{n}=2$ of 25$)$, but these observations failed to achieve statistical significance (Fisher's exact test, $p=$ 0.058). Some unhatched eggs inside the nests were found after nest excavation to be predated, presumably by ghost crabs. There were no significant differences between the number of ghost crab visits to the AMDRO-treated nests $(\mathrm{n}=14$ of 40$)$ and the number of visits to the cornmeal-treated nests ( $\mathrm{n}=9$ of 46 ; Fisher's exact test, $\mathrm{p}=0.14$ ).

Bird species observed on Juno Beach throughout this study included yellow-crowned night herons Nyctanassa violacea, tricolored herons Egretta tri-
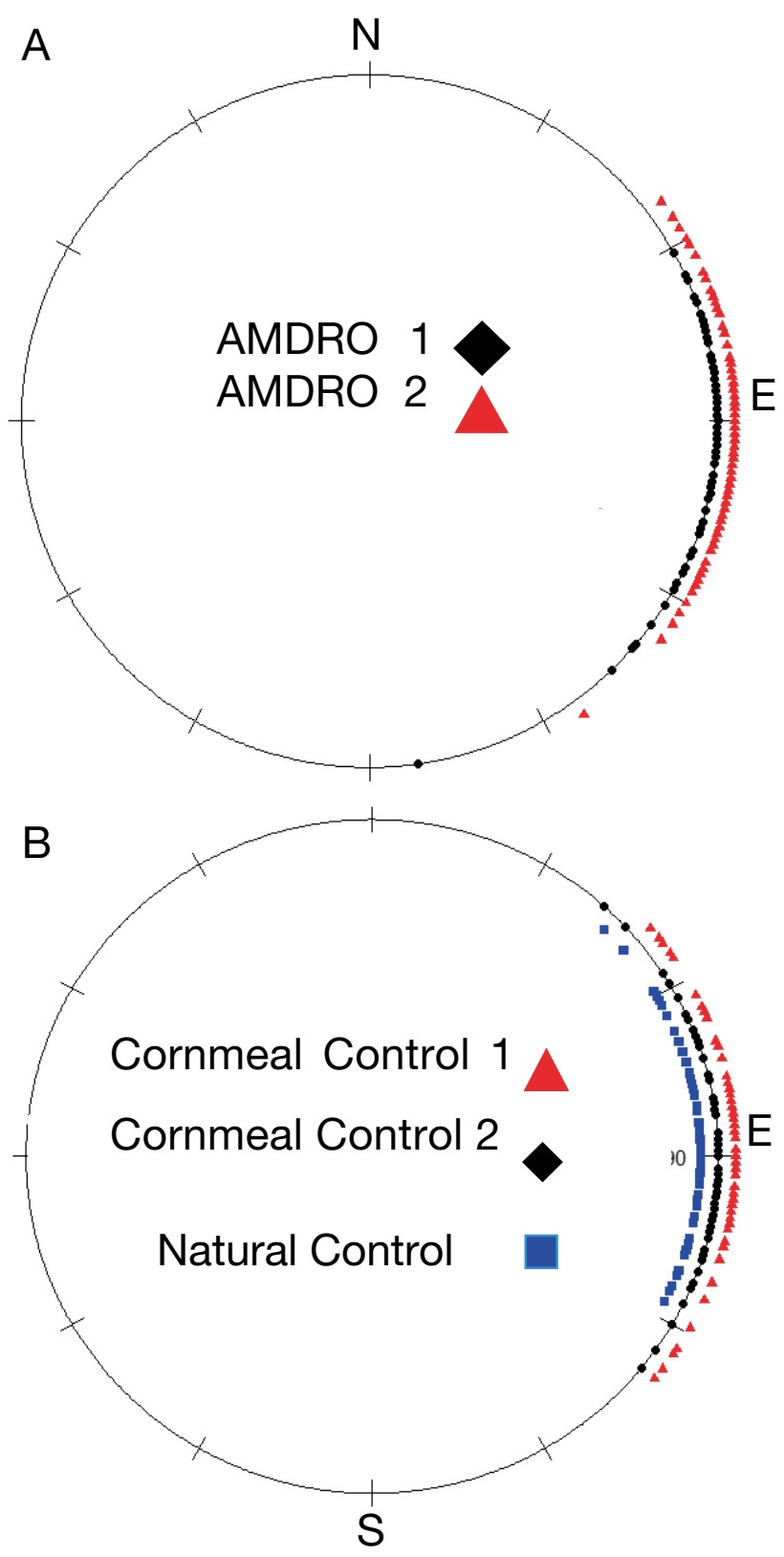

Fig. 2. Orientation angles for the individual hatchlings in the (A) AMDRO treatment groups and (B) control groups. Normal seaward orientation at Juno Beach is eastward. The crawls shown by the hatchlings in each treatment group were on average significantly oriented in that direction (see Table 2). N: North; E: East; S: South

color, American crows Corvus brachyrhynchos, and gulls Larus spp. Birds were observed waiting for hatchlings to emerge from nests, and attempting to predate hatchlings enclosed in cages, but were not observed actively predating hatchlings. This is likely due to the disturbance caused by ATVs during the continuous checking of nests. AMDRO and cornmeal 
Table 2. Second order mean orientation angles (average of the means shown by the individual nests within that treatment group) and the range of r-vectors observed among the nests tested in each treatment group

\begin{tabular}{|lccccc|}
\hline $\begin{array}{l}\text { Treatment } \\
\text { group }\end{array}$ & $\begin{array}{c}\text { No. of } \\
\text { nests }\end{array}$ & $\begin{array}{c}\text { No. of } \\
\text { hatchlings }\end{array}$ & $\begin{array}{c}\text { Second-order } \\
\text { mean angle }\end{array}$ & $\begin{array}{c}\text { r-vector } \\
\text { range }\end{array}$ & $\begin{array}{c}95 \% \text { confi- } \\
\text { dence limits }\end{array}$ \\
\hline AMDRO 1 & 7 & 134 & $89.6^{\circ}$ & $0.93-0.97$ & $88^{\circ}-96^{\circ}$ \\
AMDRO 2 & 6 & 97 & $86.4^{\circ}$ & $0.95-0.98$ & $78^{\circ}-96^{\circ}$ \\
Cornmeal 1 & 5 & 94 & $93.7^{\circ}$ & $0.95-0.98$ & $88^{\circ}-98^{\circ}$ \\
Cornmeal 2 & 5 & 88 & $92.3^{\circ}$ & $0.92-0.99$ & $82^{\circ}-103^{\circ}$ \\
Natural control & 5 & 87 & $92.2^{\circ}$ & $0.97-0.98$ & $84^{\circ}-100^{\circ}$ \\
\hline
\end{tabular}

Table 3. Numbers of predator observations by treatment type. $\mathrm{n}=$ total number of nests in each group

\begin{tabular}{|lcccccc|}
\hline Treatment & $\mathrm{n}$ & $\begin{array}{c}\text { Ghost } \\
\text { crab }\end{array}$ & Bird & Ant Mammal & Total \\
\hline AMDRO 1, 2 & 40 & 15 & 7 & 1 & 0 & 23 \\
Cornmeal 1, 2 & 46 & 9 & 1 & 4 & 1 & 15 \\
Natural control & 25 & 2 & 0 & 1 & 1 & 4 \\
\hline
\end{tabular}

treatments attracted more bird predators than were seen at the natural control nests, but this finding did not achieve statistical significance (Fisher's exact test, $\mathrm{p}=0.20$ ). Bird tracks were observed at $9.3 \%$ of the AMDRO and cornmeal treatment nests $(\mathrm{n}=8$ of 86) compared to $0 \%$ of control nests. Birds are visual predators and were likely attracted to the site by the cornmeal or AMDRO granules. Birds were more prevalent at AMDRO-treated nests $(\mathrm{n}=7$ of 40 ) than cornmeal-treated nests ( $\mathrm{n}=1$ of 46 ; Fisher's exact test, $\mathrm{p}=0.02$ ).

RIFAs were observed at $5.8 \%$ of AMDRO/cornmeal treatment nests ( $\mathrm{n}=5$ of 86 ) compared to $4.0 \%$ of natural control nests ( $\mathrm{n}=1$ of 25 ). This sample size was too small to show a significant effect (Fisher's exact test, $p>0.99$ ). Mammalian nest predation (coyote Canis latrans, and an unknown small mammal) occurred at 1 cornmeal nest and 1 natural control nest (Table 3).

\section{DISCUSSION}

The results of this study indicate that use of AMDRO on nesting beaches has no direct negative impact on loggerhead sea turtle hatching success, emergence success, or seafinding orientation behavior. Its use, either at the turtle or at the ant nest (if it can be found), might therefore be favored because it eventually kills fire ants and those insects that signif- icantly impact hatchling emergence success and survival. Moulis (1997 in Allen et al. 2001) found that loggerhead sea turtles experience a $15 \%$ decrease in emergence success when nests are infested with RIFAs at the time of emergence. Using the freshwater turtle Pseudemys nelsoni as a surrogate species, Allen et al. (2001) reported an average $33 \%$ reduction in hatchling survival from nests exposed to RIFAs compared to controls. Mortality due to RIFAs may also be significantly underestimated; $50 \%$ of $P$. nelsoni hatchlings that were stung by RIFAs had successfully emerged from their nests and reached the water before perishing from the stings (Allen et al. 2001). Likewise, Krahe et al. (2003) found that hatchling loggerhead sea turtles which emerged successfully from their nests suffered increased mortality from even a single RIFA sting.

Hatchling sea turtles delay their emergence to avoid predators and high daytime temperatures, which can be lethal (Mrosovsky 1968). Hatchlings congregate just below the surface of the sand until sand temperatures cool, and then emerge synchronously at night (Godfrey \& Mrosovsky 1997). This behavior alleviates their risk to day-active, visually hunting predators and to harmful daytime temperatures, but delayed emergence may put them at a higher risk of predation or lethal injury by fire ants, necessitating the physical removal of ant mounds or the use of pesticides such as hydramethylnon at nesting beaches with high RIFA densities.

\subsection{Nest survival and productivity}

The mean hatching and emergence success observed in the present study are typical of hatchling production from south Florida nesting beaches (Brost et al. 2015), but an increase in the frequency of nest predators near treated nests, compared to the natural control nests, was an unexpected finding in our study.

There was no significant difference between the number of ghost crab observations at AMDROtreated nests and cornmeal-treated nests, a finding consistent with previous research showing that ghost crabs primarily locate food by smell (Wellins et al. 1989, Harris et al. 2019). The scent of the cornmeal carrier could be a ghost crab attractant. While an increase in ghost crab activity did not lead to a 
noticeable reduction in hatching and emergence success in this study, ghost crab predation could be a serious problem at other nesting beaches. On small oceanic islands, ghost crabs are the primary nest predators of sea turtles. Marco et al. (2015) found that 33 eggs per nest, on average, were predated by ghost crabs on the island of Boa Vista, one of the largest loggerhead rookeries in the world and the largest in the Cape Verde Islands, in the Atlantic Ocean. They also determined that nests were most vulnerable to ghost crab predation after 40 days of incubation. This coincides with the currently recommended timeframe for application of fire ant baits to sea turtle nesting beaches.

Birds were observed at more treatment than natural control nests. Birds are visual predators and were likely attracted to the sight of the cornmeal or AMDRO granules. The cornmeal and AMDRO granules were covered with a thin layer of sand, but were often observed to be uncovered the following day due to wind or rain. Birds were more prevalent at AMDRO-treated nests than cornmealtreated nests. This finding was expected, considering that birds are primarily visual predators and were likely attracted to the bright yellow AMDRO granules that were much larger than the cornmeal granules. While hatchling sea turtles primarily emerge at night, some diurnal bird species are known to prey on sea turtle hatchlings that emerge in the early morning or whose nests are exposed (Burger \& Gochfield 2014).

A further consideration is that an increase in ghost crab and avian predators to our nest sites did not translate to a reduction in hatching or emergence success because these predators often kill hatchlings as they make their way from their nest to the ocean, after they have successfully emerged from the nest. Erb \& Wyneken (2019) estimated a nest-to-surf mortality of approximately $6 \%$ in loggerhead hatchlings from several nesting beaches on the east coast of Florida. Ghost crabs were found to be the predominant predators on a majority of nesting beaches surveyed. Hatchlings killed between the nest and the water line do not affect measurements of hatching or emergence success, and so estimates of hatching or emergence success are possibly underestimating the negative impact of placing a potential predator attractant on or near to the nest.

As expected, AMDRO also attracted fire ants. However, fire ant predation rates are low on Juno Beach and it was therefore difficult to show a significant relationship between pesticide treatments and ant depredation rates. One nest was nearly com- pletely predated by ants. This nest emerged early (46 d) after receiving 1 dose of AMDRO at Day 45. Prior to treatment, there were no signs of fire ants at this nest. During nest checks following treatment, ants were observed covering the surface of the nest and digging tunnels downward. During excavation, 66 eggs were discovered pipped but dead, and the emergence success of this nest was $3.41 \%$. The ants disappeared between the time of emergence and excavation date. This nest was located near the dune, possibly in an area of high ant activity, and may have been depredated regardless of AMDRO treatment.

No studies have examined the efficacy of AMDRO at increasing the emergence success of sea turtles. In the present study, AMDRO had no effect on the emergence success of loggerhead nests. Fire ants are not commonly abundant at Juno Beach (LMC, pers. comm.), so no conclusions can be drawn about the pesticide's efficacy based on this study. Our primary aim was to investigate the impact of hydramethylnon on the behavior and hatching and emergence success of loggerhead sea turtles rather than to examine the efficacy of hydramethylnon; thus, a study site with a high nesting density of loggerheads and a low density of fire ants was preferred. Anecdotal evidence indicates that caution should be used when administering this pesticide at other sea turtle nesting beaches. Because hydramethylnon exhibits delayed toxicity, with lethal effects taking up to a week to occur, placing the pesticide too late during incubation could have the unintended consequence of drawing fire ants to the nests and only killing them after the turtles have emerged. The sight or smell of the cornmeal/soybean oil carrier could also be an attractant to other unexpected predators (e.g. crabs, birds), which could translate into a reduction in hatchling productivity at beaches with higher predator densities than Juno Beach (e.g. Clam Pass Park South, Florida; 'B' Key, Collier County, Florida; Allen et al. 2001). It is also possible that the delayed toxicity of AMDRO could affect the hatchlings after they have emerged from the nest and successfully navigated to the water, but those effects were beyond the scope of this study.

\subsection{Orientation behavior}

The orientation behavior observed in this study is consistent with reports from previous studies dealing with the orientation of loggerhead sea turtles on the southeast coast of Florida (Salmon et al. 1995, Reintsma et al. 2014). Those results indicate that the 
hatchlings used in this study were behaving normally and are likely representative of normally orienting loggerhead turtles. If exposure to AMDRO had produced visual impairment, an ability to orient so accurately under these low light conditions would be unlikely. We conclude that AMDRO had no behaviorally significant effect on the visually mediated process of sea finding in loggerhead sea turtle hatchlings, despite visual impacts seen in other organisms.

\section{CONCLUSIONS}

The findings of this study indicate that while the use of AMDRO on nesting beaches likely does not represent a direct threat to the hatching success, emergence success, or behavior of loggerhead sea turtles, caution should still be exercised when applying this pesticide to nesting beaches because of its potential for attracting predators to the nest site.

On some rookery beaches, such as Juno Beach, the incidence of all predators is low enough that this attractant might not result in a reduction in hatchling productivity. However, not all nesting beaches have the same predator profile, and the use of this pesticide should be weighed heavily against the type and abundance of predators on the individual nesting beach in question. We recommend that when the use of AMDRO is warranted, it be applied only to locations where ants are actively foraging, such as along track lines, and hidden from the sight of visual predators. We hope that this study will help to inform wildlife management personnel, with the result that they select the best option with regard to the use of this pesticide at sites where sea turtles place their nests.

Acknowledgments. This study was undertaken by H.E.S. in partial fulfillment of the requirements for a Master's degree in biology from Florida Atlantic University (FAU). She thanks her thesis committee (Jeanette Wyneken and Sarah Milton) for their thoughtful comments and critiques. Thanks also to Adrienne McCracken, Jennifer Reilly, and all seasonal field technicians for facilitating work at Juno Beach. This project was funded in part by a grant awarded from the Sea Turtle Grants Program (\#18-002R) to J.R.P. The Sea Turtle Grants Program is funded from proceeds from the sale of the Florida Sea Turtle License Plate (www.helpingseaturtles.org). Supplemental funding came from the National Save the Sea Turtle Foundation of Ft. Lauderdale, Florida. This research was permitted by the Florida Fish and Wildlife Conservation Commission (Marine Turtle Permit \# 205 to J.R.P.) and approved by the FAU IACUC committee (protocol A18-16).

\section{LITERATURE CITED}

Allen CR, Forys EA, Rice KG, Wojcik D (2001) Effects of fire ants (Hymenoptera: Formicidae) on hatching turtles and prevalence of fire ants on sea turtle nesting beaches in Florida. Fla Entomol 84:250-253

* Allen CR, Birge HE, Slater J, Wiggers E (2017) The invasive ant, Solenopsis invicta, reduces herpetofauna richness and abundance. Biol Invasions 19:713-722

Allison D, Griffin E, Miller KL, Rider S (2009) U.S. sea turtles: a comprehensive overview of six troubled species. Oceana 1-36. https://usa.oceana.org/sites/default/files/reports/U.S. Sea_Turtles_Report_FINAL1.pdf (accessed May 2019)

Brost B, Witherington B, Meylan A, Leone E, Ehrhart L, Bagley D (2015) Sea turtle hatchling production from Florida (USA) beaches, 2002-2012, with recommendations for analyzing hatching success. Endang Species Res 27:53-68

Buhlmann KA, Coffmann G (2001) Fire ant predation of turtle nests and implications for the strategy of delayed emergence. J Elisha Mitchell Sci Soc 117:94-100

* Burger J, Gochfield M (2014) Avian predation on olive ridley (Lepidochelys olivacea) sea turtle eggs and hatchlings: avian opportunities, turtle avoidance, and human protection. Copeia 2014:109-122

Conners JS (1998) Opheodrys aestivus (rough green snake). Egg predation. Herpetol Rev 29:243

* de Solla SR, Martin PA, Mikoda P (2011) Toxicity of pesticide and fertilizer mixtures simulating corn production to eggs of snapping turtles (Chelydra serpentina). Sci Total Environ 409:4306-4311

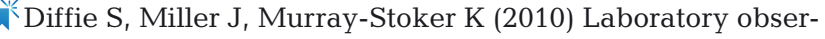
vations of red imported fire ant (Hymentopera: Formicidae) predation on reptilian and avian eggs. J Herpetol 44:294-296

Dziadzio MC, Chandler RB, Smith LL, Castleberry SB (2016) Impacts of red imported fire ants (Solenopsis invicta) on nestling and hatchling gopher tortoises (Gopherus polyphemus) in southwest Georgia, USA. Herpetol Conserv Biol 11:527-538

Environmental Protection Agency (1998) Reregistration eligibility decision (RED) Hydramethylnon. EPA Publication No. 738-R-98-023. US Environmental Protection Agency, Washington, DC.

*Erb V, Wyneken J (2019) Nest-to-surf mortality of loggerhead sea turtle (Caretta caretta) hatchlings on Florida's East Coast. Front Mar Sci 6:271

FWC (Florida Fish and Wildlife Conservation Commission) (2016) Florida Fish and Wildlife Conservation Commission Marine turtle conservation handbook. https:// myfwc.com/license/wildlife/marine-turtle-permit/

Fowler LE (1979) Hatching success and nest predation in the green sea turtle, Chelonia mydas, at Tortuguero, Costa Rica. Ecology 60:946-955

Godfrey MH, Mrosovsky N (1997) Estimating the time between hatching of sea turtles and their emergence from the nest. Chelonian Conserv Biol 2:581-585

*Harris LR, Harris KA, Nel R (2019) Food preferences of two sandy beach scavengers with different foraging strategies. Estuar Coast Shelf Sci 219:120-127

Krahe HB, Wetterer JK, Wood LH (2003) Impact of fire ant stings on hatchling sea turtle survival. In: Seminoff JA (compiler) Proc 22nd Annu Symp Sea Turtle Biol Conserv, 4-7 April 2002, Miami, FL. NOAA Tech Memo NMFSSEFSC-503, p 211-212 
Laloë JO, Esteban N, Berkel J, Hays GC (2016) Sand temperatures for nesting sea turtles in the Caribbean: implications for hatchling sex ratios in the face of climate change. J Exp Mar Biol Ecol 474:92-99

Lim LO (2004) Hydramethylnon risk characterization document. Medical Toxicology Branch, Department of Pesticide Regulation, California Agency of Environmental Protection, Sacramento, CA

Lucas M, Salmon M, Fritz E, Wyneken J (1992) Seafinding by hatchling sea turtles : role of brightness, silhouette and beach slope as orientation cues. Behaviour 122: 56-77

Marcó MVP, Larriera A, Piña CI (2013) Impacts of red imported fire ants Solenopsis invicta on survivorship of hatchlings of the broad-snouted caiman Caiman latirostris. Zool Stud 52:1-7

Marco A, da Graca J, Garcia-Cerda R, Abella E, Freitas R (2015) Patterns and intensity of ghost crab predation on the nests of an important endangered loggerhead population. J Exp Mar Biol Ecol 468:74-82

Mazaris AD, Schofield G, Gkazinou C, Almpanidou V, Hays GC (2017) Global sea turtle conservation successes. Sci Adv 3:e1600730

McFarlane RW (1963) Disorientation of loggerhead hatchlings by artificial road lighting. Copeia 1963:153

Miller J (1999) Determining clutch size and hatching success. In: Eckert KL, Bjorndal KA, Abreu-Grobois FA, Donnelly M (eds) Research and management techniques for the conservation of sea turtles. Publication No. 4, IUCN/SSC Marine Turtle Specialist Group, Blanchard, PA, p 124-129

Mount RH, Trauth SE, Mason WH (1981) Predation by the red imported fire ant, Solenopsis invicta (Hymenoptera: Formicidae), on eggs of the lizard Cnemidophorus sexlineatus (Squamata: Teiidae). J Ala Acad Sci 52:66-70

Mrosovsky N (1968) Nocturnal emergence of hatchling sea

Editorial responsibility: Matthew Godfrey,

Beaufort, North Carolina, USA turtles: control by thermal inhibition of activity. Nature 220:1338-1339

* Parris LB, Lamont MM, Carthy RR (2002) Increased incidence of red imported fire ant (Hymenoptera: Formicidae) presence in loggerhead sea turtle (Testudines: Cheloniidae) nests and observations of hatchling mortality. Fla Entomol 85:514-517

Perrault JR, Wyneken J, Thompson LJ, Johnson C, Miller DL (2011) Why are hatching and emergence success low? Mercury and selenium concentrations in nesting leatherback sea turtles (Dermochelys coriacea) and their young in Florida. Mar Pollut Bull 62:1671-1682

Reintsma N, Young M, Salmon M (2014) Do lighthouses disrupt the orientation of sea turtle hatchlings? Hypothesis testing with arena assays at Hillsboro Beach, Florida, U.S.A. Mar Turtle Newsl 140:1-3

Robins JB (1995) Estimated catch and mortality of sea turtles from the East Coast otter trawl fishery of Queensland, Australia. Biol Conserv 74:157-167

Salmon M, Tolbert MG, Painter DP, Goff M, Reiners R (1995) Behavior of loggerhead sea turtles on an urban beach. II. Hatchling orientation. J Herpetol 29:568-576

Tomlin CDS (2003) The pesticide manual: a world compendium:, 13th edn. British Crop Protection Council, Altonp 541-542

Wellins CA, Rittschoff D, Wachowiak M (1989) Location of volatile odor sources by the ghost crab Ocypode quadrata (Fabricius). J Chem Ecol 15:1161-1169

Wilder SM, Holway DA, Suarez AV, LeBrun EG, Eubanks MD (2011) Intercontinental differences in resource use reveal the importance of mutualisms in fire ant invasions. Proc Natl Acad Sci 108:20639-20644

Wu B, Liang L, Ma L, Du W (2016) Effects of pesticide exposure on embryonic development and hatchling traits of turtles. Asian Herpetol Res 7:28-33

Zar G (1999) Biostatistical analysis. Princeton-Hall, Upper Saddle River, NJ

Submitted: August 24, 2019; Accepted: February 21, 2020

Proofs received from author(s): March 20, 2020 